\title{
Yves Bonnefoy, Terre intraviste. Poesie 1953-2006
}

\section{Valentina Ponzetto}

\section{(2) OpenEdition}

\section{Journals}

\section{Edizione digitale}

URL: https://journals.openedition.org/studifrancesi/46304

DOI: 10.4000/studifrancesi.46304

ISSN: 2427-5856

\section{Editore}

Rosenberg \& Sellier

\section{Edizione cartacea}

Data di pubblicazione: 1 octobre 2007

Paginazione: 478

ISSN: 0039-2944

\section{Notizia bibliografica digitale}

Valentina Ponzetto, «Yves Bonnefoy, Terre intraviste. Poesie 1953-2006», Studi Francesi [Online], 152 (LI I

II) | 2007, online dal 30 novembre 2015, consultato il 24 novembre 2021. URL: http://

journals.openedition.org/studifrancesi/46304 ; DOI: https://doi.org/10.4000/studifrancesi.46304

Questo documento è stato generato automaticamente il 24 novembre 2021.

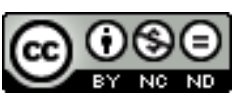

Studi Francesi è distribuita con Licenza Creative Commons Attribuzione - Non commerciale - Non opere derivate 4.0 Internazionale. 


\title{
Yves Bonnefoy, Terre intraviste. Poesie 1953-2006
}

\author{
Valentina Ponzetto
}




\section{NOTIZIA}

YVES BONNEFOY, Terre intraviste. Poesie 1953-2006. Traduzione e cura di Fabio scotTo, Venezia, Edizioni del Leone, 2006, pp. 124.

1 Terre intraviste è più di una semplice edizione italiana con testo a fronte di un volume di poesie di Yves Bonnefoy. Si tratta infatti di una scelta di opere tratte da diverse raccolte, riunite in un percorso originale concordato dall'autore stesso con Fabio Scotto, che è ormai da anni uno dei suoi più fedeli interpreti e traduttori (ricordiamo in particolare le numerose traduzioni già pubblicate presso diversi editori e il Cahier Yves Bonnefoy di cui è stato curatore nel 2003 per la rivista francese «Europe»). Le liriche così accostate tracciano un'ideale parabola dell'intero percorso creativo del poeta, dagli esordi legati al surrealismo di Du mouvement et de l'immobilité de Douve (1933) fino a oggi. Un oggi di estrema attualità, per di più, un passo avanti rispetto alle stesse edizioni francesi: a chiudere il volume troviamo in effetti una sezione di quattro poesie inedite, su cui varrà la pena di soffermarsi anche per il loro intenso rapporto con la tradizione letteraria e in particolare con quella italiana. Riproponendo in poesia il genere musicale del tombeau Bonnefoy ci offre qui quattro evocativi omaggi ad altrettanti grandi poeti scomparsi: Baudelaire, Leon Battista Alberti, Mallarmé e Leopardi. Inoltre, pur mantenendo un moderno verso libero, egli sceglie di adattarlo in questo caso alla più consacrata delle forme, quella del sonetto, rimando al contempo agli illustri scrittori cantati, ma anche alla personale recente esperienza di traduttore di Petrarca e di Shakespeare. A fronte dei versi di Bonnefoy Fabio Scotto, poeta egli stesso, ci offre una traduzione di grande sensibilità e finezza, che prolunga e arricchisce questo ideale dialogo fra poeti al di là delle frontiere e delle generazioni. 